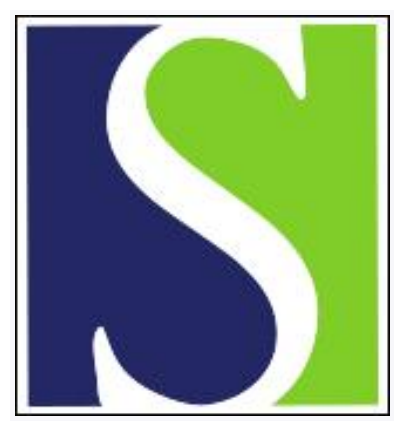

Scand J Work Environ Health 2015;41(5):506-507

https://doi.org/10.5271/sjweh.3518

Published online: 06 Aug 2015, Issue date: 01 Sep 2015

Authors' reply: Calculation of population attributable risk should to be based on robust estimates

by Kivimäki M, Nyberg ST, Kawachi I

Affiliation: Department of Epidemiology and Public Health, University College London, UK. m.kivimaki@ucl.ac.uk

Refers to the following text of the Journal: 2015;41(5):504-505

The following articles refer to this text: 2016;42(3):251-255;

2017;43(1):5-14

Key terms: IPD; IPD-Work Consortium; PAR; PAR calculation; population attributable risk

This article in PubMed: www.ncbi.nlm.nih.gov/pubmed/26247405 


\section{Authors' reply: Calculation of population attributable risk should to be based on robust estimates}

We are pleased that the findings of the IPD-Work Consortium continue to generate discussion among occupational health researchers. In his letter to the editor, Ingre used age and sex-adjusted data from the appendix of our paper (1) to calculate population attributable risk (PAR) for job control (2). The results led him to ask whether job control may be more important than job strain as a risk factor for coronary heart disease. In this response, we summarize data from the Consortium suggesting that the answer to Ingre's question is likely to be "no".

PAR is a tool used to assess the extent to which removing a risk factor might reduce disease events. An underlying assumption in the PAR calculation is that the estimated risk is truly causal and not confounded. By using only age and sex-adjusted risk estimates, Ingre omitted adjustment for socioeconomic status (SES), which would have been a highly relevant confounding factor in this context. SES and job control are correlated with each other. That is, the labor market sorts individuals into occupations with high or low job control according to their educational qualifications. Occupations involving more decision authority and skill utilization (ie, job control) require more educational qualifications. Low SES is additionally a marker for a range of risk factors other than low job control. These include, for example, a higher exposure to adverse life events in childhood, poorer residential neighborhood in adulthood, poorer nutrition, higher prevalence of obesity, and increased systemic inflammation, all of which are associated with increased coronary heart disease risk (3-6). If the relationship between job control and heart disease is not adjusted for SES, then the effect estimate will become unrealistically high as it reflects not only the adverse impacts of low job control but also exposures associated with low SES.

In figure 1, we used data from the appendix of the IPD-Work Consortium paper to provide evidence for this reasoning (1). The age and sex-adjusted hazard ratio of incident coronary heart disease is 1.16 [95\% confidence interval (95\% CI) 1.05-1.27] for low compared with high job control (median split). When the association is additionally adjusted for SES, the hazard ratio attenuates to the null: 1.04 (95\% CI 0.94-1.15). The reduction in estimated excess risk after this adjustment is $75 \%$, suggesting major confounding by SES. In a sensitivity analysis, the pattern of results is similar when treating job control as a continuous score: age and sex-adjusted

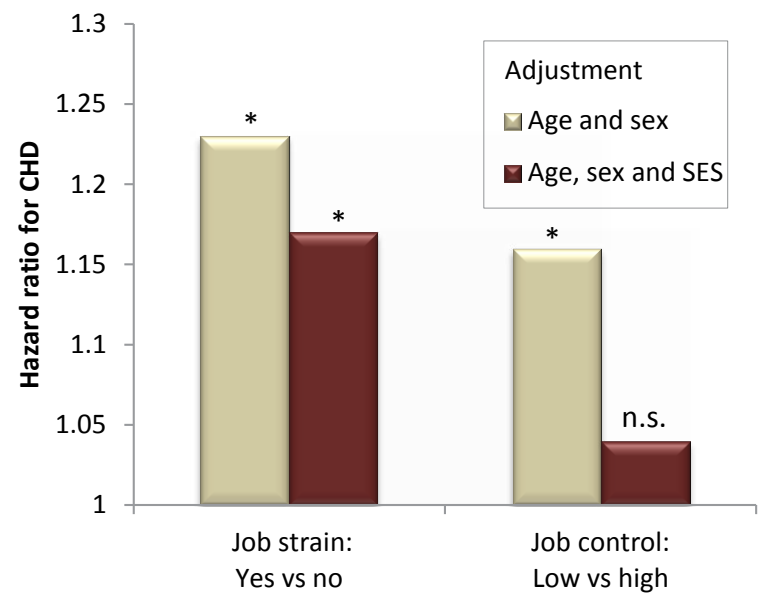

Figure 1. Associations of job strain and low job control with incident coronary heart disease before and after adjustment for socioeconomic status in the IPD-Work study. * Statistically significant $(P<0.05)$ and n.s. refers to statistically non-significant hazard ratio.

hazard ratio per 1 standard deviation decrease in job control is statistically significant $(1.08,95 \%$ CI $1.02-$ 1.12 ) but age, sex, and SES-adjusted hazard ratio is not (1.01, 95\% CI 0.93-1.09).

The results on job strain and coronary heart disease are strikingly different; this association is not confounded by SES (figure 1). The age and sex-adjusted hazard ratio of coronary heart disease for job strain versus no job strain is 1.23 (95\% CI 1.08-1.39). After additional adjustment for SES, the hazard ratio remains statistically significant at 1.17 (95\% CI 1.05-1.31). The association between job strain and coronary heart disease also remains after adjustments for a range of lifestyle and standard biological risk factors (1-7).

Ingre suggests that there is probably no multiplicative interaction between job control and job demands in predicting coronary heart disease. However, the fact that job strain is robustly associated with coronary heart disease (even though job control is not) suggests that job strain is a better predictor of coronary heart disease irrespective of such interactions.

It might also be useful briefly to assess evidence from studies other than IPD-Work. The consistency of findings across different studies conducted with different samples and in different contexts strengthens 
the likelihood of a causal relation (8). The association between job strain and coronary heart disease has shown to be consistent across studies initiated at different time periods and from different geographical regions $(1,9)$. In contrast, findings on job control are heterogeneous: some studies suggest that job control is more important than job demands while other studies report that job demands are more important $(10,11)$. This could be expected because the confounding structure, including the distribution of SES, tends to vary between studies producing heterogeneous findings for confounded associations.

We hope this reply has made it clear that the IPDwork consortium provides support for the job strain model.

\section{References}

1. Kivimäki M, Nyberg ST, Batty GD, Kivimäki M, Nyberg ST, Batty GD, Fransson EI, Heikkilä K, Alfredsson L et al. Job strain as a risk factor for coronary heart disease: a collaborative meta-analysis of individual participant data. Lancet. 2012; 380: 1491-7. http://dx.doi.org/10.1016/S0140-6736(12)60994-5

2. Ingre M. Excuse me, but did the IPD-work consortium just falsify the job-strain model? Scand J Work Environ Health. 2015;41(5):504-505. http://dx.doi.org/10.5271/sjweh.3512

3. Mayen AL, Marques-Vidal P, Paccaud F, Bovet P, Stringhini $\mathrm{S}$. Socioeconomic determinants of dietary patterns in low- and middle-income countries: a systematic review. Am J Clin Nutrition. 2014; 100: 1520-31. http://dx.doi.org/10.3945/ ajcn.114.089029

4. Halonen JI, Stenholm S, Pentti J, Halonen JI, Stenholm S, Pentti J, Kawachi I, Subramanian SV, Kivimäki M, et al. Childhood Psychosocial Adversity and Adult Neighborhood Disadvantage as Predictors of Cardiovascular Disease: A Cohort Study. Circulation. 2015 [ePub ahead of print]. http:// dx.doi.org/10.1161/CIRCULATIONAHA.115.015392
5. Stringhini S, Batty GD, Bovet P, Stringhini S, Batty GD, Bovet P, Shipley MJ, Marmot MG, Kumari M, et al. Association of lifecourse socioeconomic status with chronic inflammation and type 2 diabetes risk: the Whitehall II prospective cohort study. PLoS Med. 2013; 10: e1001479. http://dx.doi.org/10.1371/ journal.pmed.1001479

6. McLaren L. Socioeconomic status and obesity. Epidemiol Rev. 2007; 29: 29-48. http://dx.doi.org/10.1093/epirev/mxm001

7. Kivimäki M, Nyberg ST, Fransson EI, Kivimäki M, Nyberg ST, Fransson EI, Heikkilä K, Alfredsson L, Casini A, et al. Association of job strain and lifestyle factors with the risk of coronary artery disease: a meta-analysis of individualparticipant data Can Med Assoc J (CMAJ). 2013; 185:763-9.

8. Bradford Hill A. The environment and disease: Association or causation? Proc R Soc Med 1965; 58: 295-300.

9. Steptoe A, Kivimäki M. Stress and cardiovascular disease: an update on current knowledge. Annu Rev Public Health 2013; 34: 337-54. http://dx.doi.org/10.1146/annurevpublhealth-031912-114452

10. Everson-Rose SA, Lewis TT. Psychosocial factors and cardiovascular diseases. Annu Rev Public Health. 2005; 26: 469-500. http://dx.doi.org/10.1146/annurev. publhealth.26.021304.144542

11. Eller NH, Netterstrom B, Gyntelberg F, Eller $\mathrm{NH}$ Netterstrøm B, Gyntelberg F, Kristensen TS, Nielsen F, Steptoe A, et al. Work-related psychosocial factors and the development of ischemic heart disease: a systematic review. Cardiol Rev. 2009; 17: 83-97.http://dx.doi.org/10.1097/ CRD.0b013e318198c8e9

Mika Kivimäki, ${ }^{1,2,3}$ Solja T Nyberg, ${ }^{3}$ Ichiro Kawachi ${ }^{4}$

1 Department of Epidemiology and Public Health, University College London, UK.

2 Clinicum, University of Helsinki, Finland.

3 Finnish Institute of Occupational Health, Finland.

4 Department of Social and Behavioral Sciences, Harvard School of Public Health, USA.

Correspondence to Mika Kivimäki, email: m.kivimaki@ucl. ac.uk 